\title{
Localism vs. Individualism for the Scientific Realism Debate
}

\begin{abstract}
Localism is the view that the unit of evaluation in the scientific realism debate is a single scientific discipline, sub-discipline, or claim, whereas individualism is the view that the unit of evaluation is a single scientific theory. Localism is compatible, while individualism is not, with a local pessimistic induction and a local selective induction. Asay (2016) presents several arguments to support localism and undercut globalism, according to which the unit of evaluation is the set of all scientific disciplines. I argue that some of his arguments clash with localism as well as with globalism and support individualism, and that individualism goes hand in hand, while localism does not, with the basic rule of how to evaluate an argument.
\end{abstract}

\section{Keywords}

Individualism, Globalism, Collectivism, Localism, Scientific Antirealism, Scientific Realism

Park, Seungbae (2018). "Localism vs. Individualism for the Scientific Realism Debate", Philosophical Papers. https://doi.org/10.1080/05568641.2018.1500144.

Seungbae Park

Ulsan National Institute of Science and Technology

Republic of Korea

\section{Introduction}

There are many disciplines in current science, including physics, chemistry, biology, geology, and psychology. This paper concerns the issue of whether we should evaluate scientific disciplines collectively or individually. Traditionally, philosophers of science have evaluated them collectively. Their approach is called globalism. Recently, however, some philosophers (Ruhmkorff, 2013; Asay, 2016) have rejected globalism and argue that we should instead evaluate scientific disciplines locally. Their approach is called localism.

This paper is organized as follows. In Section 2, I explicate Jamin Asay's (2016) distinction between globalism and localism, arguing that localism allows for a local pessimistic induction and a local selective induction. In Section 3, I explicate the distinction between scientific collectivism and individualism (Park, 2017: 99, 2018a: 57-58, 2018b: 443-444), arguing that individualism disallows a local pessimistic induction and a local selective induction. In Section 4, I argue that some arguments that Asay has offered to support localism and undercut globalism actually clash with localism as well as with globalism and dovetail with individualism. In Section 5, I reply to objections.

The main thesis of this paper is that individualism is a better framework for the scientific realism debate than localism. It is important to adjudicate between localism and individualism because scientific realists and antirealists would be engaged in different sorts of debates, depending on whether they adopt localism or individualism as the framework for their debates.

\section{Globalism vs. Localism}

Traditionally, realists and antirealists take their epistemic attitudes towards all scientific theories collectively, defending and attacking such arguments as the no-miracles argument (Putnam, 1975: 73) and the pessimistic induction (Poincaré, 1905/1952: 160; Mach, 1911: 17; Laudan, 1977: 126; Putnam, 1978: 25; Stanford, 2006: 19-20; Wray, 2013: 4327). The nomiracles argument says that successful scientific theories are approximately true. By contrast, 
the pessimistic induction says that successful past theories were overturned, so it is likely that successful present theories will also be overturned. These two arguments have opposite conclusions, but they have a similarity, viz., they are intended to apply across the board to all successful theories in science. Thus, globalism is inherent in them. Globalism is an attempt to evaluate all scientific theories or disciplines together.

Asay (2016) rejects globalism and defends localism. Localism is an attempt to evaluate a discipline, sub-discipline, or claim independently of how other disciplines, sub-disciplines, or claims are evaluated:

The localist I seek to isolate is one who approaches scientific realism discipline by discipline. (Or, as the case may require, sub-discipline by sub-discipline.) The localist might adopt structural realism about quantum physics, but realism about biology and constructive empiricism about psychology. (Asay, 2016: 4)

Asay also says that we can evaluate "single, individual theses" (2016: 16). Thus, localism, as defined by Asay, allows for the evaluation of an entire discipline, say, physics, chemistry, biology, or psychology, allows for the evaluation of each sub-discipline of those disciplines, and allows for the evaluation of a single scientific claim, such as "Continents move around" and "Water is $\mathrm{H}_{2} \mathrm{O}$."

What sort of debate would realists and antirealists be engaged in under the localist framework? Asay says that consistent "success and continuity in some domains can lead to a successful but localized no miracles argument, while consistent scientific revolutions in others can lead to a successful but localized pessimistic induction" (2016: 16). For example, realists would argue that Maxwell's electromagnetic theory is true on the grounds that its success would be a miracle if it were false. This no-miracle argument is local in that it applies only to the electromagnetic theory. Pessimists would object that the electromagnetic theory will be abandoned, just as its predecessors, viz., the classical particle theory and Fresnel's wave theory, were abandoned. This pessimistic induction is also local in that it applies only to theories of light. Realists and antirealists would disagree over whether the local no-miracle argument and the local pessimistic induction ${ }^{1}$ are strong or weak, but they would agree that the arguments apply only to theories of light, and that the "best way to come to the truth about scientific realism is to explore each branch of science individually on its own metaphysical and epistemological terms" (Asay, 2016: 4).

Just as there is a local pessimistic induction as well as a global pessimistic induction, so there is a local selective induction as well as a global selective induction. According to a global selective induction, since the same kind of theoretical claims was preserved across all scientific disciplines, that kind of theoretical claims will be preserved across all scientific disciplines. Different selectivists ${ }^{2}$ identify different kinds of theoretical claims as stable. John Worrall (1989) observes that a mathematical equation was preserved in the transition from Fresnel's ether theory to the electromagnetic theory. Philip Kitcher (1993: 140-149) observes that a working posit was preserved in the transition from the ether theory to the electromagnetic theory. Stathis Psillos (1999: Chapter 5) observes that a working posit was preserved in the transition from the caloric theory to the kinetic theory. Pierre Cruse and David Papineau (2002) observe that a Ramsey sentence was preserved in the transition from the ether theory to the electromagnetic theory. These philosophers' examples of preserved theoretical claims are intended to be representative of the population of all preserved

\footnotetext{
1 See Samuel Ruhmkorff (2013) for a real example of local pessimistic induction.

2 Selectivists are usually called selective realists. As P. Kyle Stanford (2015: 876) maintains, however, it is not clear whether they deserve the appellation 'realists.'
} 
theoretical claims in science. By contrast, according to a local selective induction, since a certain kind of theoretical claims was preserved in a discipline or sub-discipline, that kind of theoretical claims will be preserved in that discipline or sub-discipline. This local selective induction applies only to that discipline or sub-discipline, and hence it is compatible with the situation in which in a certain discipline or sub-discipline, a mathematical equation is preserved; in another, a working posit; in another, a Ramsey sentence; in another, both a working posit and a Ramsey sentence; and in another, no theoretical claim.

A local selective induction has an advantage over a global selective induction. A local selective induction remains unscathed, even if the humoral theory, the miasma theory, and the germ theory do not have a common theoretical constituent, and even if upon reflecting "on the vast complexities of various historical episodes in science, there is no reason to think that the general assumptions one finds will be at all simple, natural, or even non-disjunctive" (Magnus and Callender, 2004: 335). These observations of the history of diverse disciplines refute a global selective induction, but not a local selective induction. Local selectivists can cheerfully grant that a certain discipline does not preserve any theoretical claim, and that different disciplines preserve different kinds of theoretical claims.

In sum, localism is compatible with a local no-miracle argument, a local pessimistic induction, and a local selective induction. Local realists and antirealists are engaged in debates over whether such arguments are tenable, subjecting them to the tribunal of the history of science. Thus, the history of science acts as an arbiter between local realists and antirealists, just as it does between global realists and antirealists.

\section{Collectivism vs. Individualism}

Scientific collectivism and individualism hold, respectively, that we should evaluate scientific theories collectively and individually, i.e., that the unit of evaluation is a set of scientific theories and a single theory, respectively (Park, 2017: 99, 2018a: 57-58, 2018b: 443-444). In this paper, individualism is committed to the view (Lipton, 2001: 353; Achinstein, 2002; Enfield, 2008: 891; Roush, 2010; Fitzpatrick, 2013) that scientists' arguments for scientific theories are all the evidence for scientific theories, so the epistemic status of scientific theories is not affected by philosophical arguments, such as pessimistic and selective inductions.

Globalism and collectivism make different claims about the scope of evaluation. While globalism claims that it is always all scientific theories or all scientific disciplines, collectivism claims that it might be a set of all scientific theories, a set of present theories belonging to the different disciplines, or a set of past and present theories belonging to the same discipline. Localism and individualism also make different claims about the scope of evaluation. While individualism claims that it is always a single theory, localism claims that it might be a single discipline, e.g., physics, chemistry, biology, and so forth, or a single subdiscipline, e.g., "organic chemistry, physical chemistry, and biochemistry" (Asay, 2016: 16). Or it might be "single, individual theses" (Asay, 2016: 16). Given that there are multiple theories in a discipline or sub-discipline, localism is compatible with a collective evaluation of scientific theories, whereas individualism is not.

Suppose that there are three theories $-\mathrm{T}_{1}, \mathrm{~T}_{2}$, and $\mathrm{T}_{3}-$ in the same discipline of current science. They are, say, the Big Bang theory, the kinetic theory, and the electromagnetic theory. All of them belong to physics, but they belong to different sub-disciplines of physics. According to localism, $\mathrm{T}_{1}, \mathrm{~T}_{2}$, and $\mathrm{T}_{3}$ can be evaluated together; however, according to individualism, they cannot. Local realists say that $T_{1}, T_{2}$, and $T_{3}$ are successful, so they are true. Local pessimists object that their forerunners were discarded, so they will also be discarded. Local selectivists reply that the constituents that $T_{1}, T_{2}$, and $T_{3}$ share with their 
predecessors are true. By contrast, individualists say that scientists' arguments for $\mathrm{T}_{1}, \mathrm{~T}_{2}$, and $\mathrm{T}_{3}$ are different from one another, so they should be evaluated separately. The outcome of individualists' evaluation might be the same as that of local pessimists. For example, individualists might agree with local pessimists that $T_{1}, T_{2}$, and $T_{3}$ are all unwarranted. Individualists, however, think so not on the grounds that their predecessors were unwarranted but on the grounds that scientists' arguments for them are weak, exposing specific problems with scientists' arguments for them. So individualists and localists can arrive at the same conclusion, but they rely on different premises.

Suppose now that $\mathrm{T}_{1}, \mathrm{~T}_{2}$, and $\mathrm{T}_{3}$ are successive theories in the same discipline, say, the classical particle theory, Fresnel's wave theory, and Maxwell's electromagnetic theory. As we noted before, localism allows for the local pessimistic induction that since $T_{1}$ and $T_{2}$ were thrown out, $\mathrm{T}_{3}$ will also be thrown out, and also allows for the local selective induction that since only the common theoretical constituent of $\mathrm{T}_{1}, \mathrm{~T}_{2}$, and $\mathrm{T}_{3}$ was stable, only it will be stable in future developments of their discipline. Individualism, by contrast, disallows for the local pessimistic induction and the local selective induction. Once individualists believe that scientists' arguments for $\mathrm{T}_{3}$ are strong, they believe not only that the common constituent is true but also that the other constituents of $\mathrm{T}_{3}$ are true. Once they believe that scientists' arguments for it are weak, they do not even believe that the common constituent is true. Neither the fact that $T_{1}$ and $T_{2}$ were discarded nor the fact that $T_{1}, T_{2}$, and $T_{3}$ have a common constituent makes any difference to the epistemic status of $\mathrm{T}_{3}$. The epistemic status of $\mathrm{T}_{3}$ is determined solely by the strength of scientists' arguments for it.

Under the framework of individualism, realists and antirealists are engaged with the details of scientists' arguments for a particular scientific theory. They disagree over whether the arguments are strong or weak, but they agree that being engaged with the details of scientists' arguments and evaluating them thoroughly is the only way to resolve the dispute between them. They also agree that the evaluation of scientists' arguments for a theory does not affect the evaluation of scientists' arguments for another theory, even if the two theories belong to the same discipline. The individualist framework contrasts with the localist framework under which realists and antirealists are allowed to defend and attack a local pessimistic induction and a local selective induction, which are all attempts to evaluate collectively a group of scientific theories belonging to the same discipline or sub-discipline.

Why should we choose individualism over localism as a framework for the debate between realists and antirealists? In the next section, I argue that some arguments that Asay adduces to justify localism and undermine globalism actually undermine both localism and globalism and support individualism.

\section{Individualism over Localism}

\subsection{The Argument from Diversity}

The argument from diversity, which Asay takes to be the most powerful argument for localism, holds that different disciplines postulate diverse theoretical entities, and that the diverse theoretical entities are of varying degrees of epistemic status. For example, the "ontological and epistemological issues concerning the existence of fields, quarks, and forces are distinct from those concerning mitochondria and bacteria, not to mention beliefs and desires" (Asay, 2016: 6). So lumping together all theoretical entities or scientific disciplines under the single heading of scientific realism "is bound to ignore and erase the very real differences between the different scientific disciplines" (Asay, 2016: 6).

In my view, however, ontological and epistemic differences exist not only between present theories belonging to different disciplines but also between past and present theories belonging to the same discipline. Consider, for example, that the caloric theory and the 
kinetic theory postulate different theoretical entities: caloric and molecules. The ontological and epistemic differences between caloric and molecules are no smaller than those between fields and mitochondria. It follows that the argument from diversity supports not only the independent evaluations of present theories belonging to different disciplines but also the independent evaluations of past and present theories belonging to the same discipline.

The ontological and epistemic differences between mitochondria and strings invalidate the inference that since string theory is a collection of speculative assumptions for which there is no direct empirical evidence, molecular biology is also a bunch of speculative assumptions for which there is no direct empirical evidence. Similarly, the ontological and epistemic differences between caloric and molecules invalidate the local pessimistic induction that since the caloric theory was ousted, the kinetic theory will also be ousted, as well as the local selective induction that since only the common constituent of the two theories was stable, only that constituent will be stable.

The ontological and epistemic differences between mitochondria and strings require that we should evaluate biologists' arguments for the claims of molecular biology independently of how we evaluate physicists' arguments for string theory. Analogously, the ontological and epistemic differences between caloric and molecules require that we should evaluate kinetic scientists' arguments for the kinetic theory independently of how we evaluate caloric scientists' arguments for the caloric theory.

In sum, if realists and antirealists take Asay's argument from diversity seriously, they should reject localism and accept individualism as the framework for their debate. Individualism implies that if kinetic scientists' arguments for the kinetic theory are strong, we may accept the theory in toto despite the fact that caloric scientists' arguments for the caloric theory were weak. If kinetic scientists' arguments for the kinetic theory are weak, we may reject it in toto despite the fact that the kinetic theory has a common theoretical constituent with the caloric theory. Or we may accept only the common constituent, depending on whether scientists' arguments for it allow us to do so. Consequently, it is not localism but rather individualism that enshrines the spirit of the argument from diversity.

\subsection{The Argument from Disunity}

Reductionism and anti-reductionism hold, respectively, that special sciences are and are not reducible to physics. Asay's argument from disunity says that globalism and localism go well with reductionism and anti-reductionism, respectively. If special sciences are reducible to physics, and if you believe that physical theories are true, you should also believe that chemical theories and biological theories are true, i.e., you should be a global realist. If, however, special sciences are not reducible to physics, "one possible avenue to globalism about science is immediately shut down" (Asay, 2016: 9).

Asay observes that different sciences use different methods. For example, scientists use the method of observing phenomena in historical science, whereas scientists use the method of creating phenomena in experimental science. He says that if "different sciences use different epistemological methods, then we need to evaluate those methods on a case-by-case basis in determining what the best attitude is to take with respect to them vis-à-vis realism" (2016: 8). Thus, an argument supporting anti-reductionism supports localism.

Again, however, if realists and antirealists take Asay's argument from disunity seriously, they should reject localism and accept individualism. Ptolemaic scientists and Copernican scientists used different methods to justify their pet theories. For example, Ptolemaic scientists denied, while Copernican scientists affirmed, that a telescope correctly reflected the celestial sphere. It follows that Ptolemaic astronomy is not reducible to 
Copernican astronomy. In general, new scientists use more advanced technologies than old scientists. Therefore, an old theory is not reducible to a new theory.

In addition, to say that $T_{1}$ is reducible to $T_{2}$ means that $T_{2}$ explains $T_{1}$ (Nagel, 1979:

338). For example, statistical mechanics explains thermodynamics, and hence thermodynamics is reducible to statistical mechanics. According to Nagel, $\mathrm{T}_{1}$ is reducible to $\mathrm{T}_{2}$ when $\mathrm{T}_{1}$ is deducible from $\mathrm{T}_{2}$. Thus, his view about the condition of reduction is consistent with Carl Hempel's (1966) deductive-nomological model of explanation that some scientific explanations take the form of a deductive argument. Is the Ptolemaic theory deducible from the Copernican theory? The answer is no. So the Ptolemaic theory is not reducible to the Copernican theory.

The same goes for other successive theories, such as the pair of the phlogiston theory and the oxygen theory and the pair of the caloric theory and the kinetic theory. The old theories are not reducible to the new theories. Thus, the argument from disunity suggests that they should be evaluated separately, and that realists and antirealists should choose individualism over localism.

\subsection{The Argument from Hasty Generalizations}

The argument from hasty generalizations holds that globalism commits the fallacy of hasty generalization whereas localism does not. Worrall, for example, observes that a mathematical equation was preserved in the transitions of the theories of light in the nineteenth century. On the basis of this single case study, he generalizes that we are justified in believing in the structure of all unobservables, but not in their nature. Such a generalization is hasty. Asay says that if "the history of the theory of light is best understood along the lines that Worrall tells it, then perhaps a structuralist view about light is appropriate; but it's no argument at all that we should be structuralists about genes or epidemiology or any other area of science" (2016: 13).

In my view, however, the fallacy of hasty generalization occurs not only when our generalization is about all theories across different disciplines but also when it is about all successive theories in the same discipline. Consider the local pessimistic induction that since theories of light were unstable in the nineteenth century, all theories of light will be unstable. Such a generalization is also hasty. Consider also the local selective induction that since only a mathematical equation was preserved in the transitions of the theories of light in the nineteenth century, only a mathematical equation will be preserved in all the transitions of theories of light. Such a generalization is also hasty.

In sum, the argument from hasty generalizations conflicts with localism, but it sits well with individualism that we should evaluate even successive theories of the same discipline individually. Therefore, realists and antirealists can avoid a hasty generalization by choosing individualism over localism.

\subsection{The Argument from Other Fields of Philosophy}

Asay observes that there are realism debates in other fields of philosophy, such as ethics and aesthetics. But these fields of philosophy are homogeneous. For example, ethicists ask and answer questions like "Do moral facts inhabit the universe?" and "Can we have moral knowledge?" By contrast, science is a heterogeneous field. Cosmologists ask and answer questions like "What is the origin of the universe?" and "Are there parallel universes?" Germ theorists ask and answer questions like "How is the Zika virus transmitted?" and "How can we control super viruses?" Ethicists are interested in homogeneous questions, but cosmologists and germ theorists are interested in heterogeneous questions. 
The argument from other fields of philosophy holds that localism goes along with the realism debates in other fields of philosophy, but globalism does not. ${ }^{3}$ The scientific realism debate should go hand in hand with the realism debates in other fields of philosophy because finding "common ground with the other realism debates in philosophy is potentially quite illuminating; the closer these other realism concerns come to the realism concerns of science, the more the parties to the different debates can learn from one another" (Asay, 2016: 8).

I welcome Asay's suggestion that the participants in the scientific realism debate and those of the realism debates in other fields of philosophy should communicate with one another. In my view, the former need to know what the latter would think of pessimistic and selective inductions. Philosophers in other fields of philosophy would think of them, global or local, as unusual, given that the way they assess philosophical positions is radically different from the ways in which pessimists and selectivists assess scientific theories.

Consider, for example, that there are many views of mind in the history of philosophy of mind. They include substance dualism, philosophical behaviorism, the identity theory, functionalism, and property dualism. Each of these theories of mind is supported and undermined by arguments that rivaling philosophers have constructed for and against it. Philosophers of mind engage with the details of arguments for a theory of mind to determine their attitudes towards it. They accept or reject, for example, property dualism, depending on whether property dualists' arguments for it are strong or weak. Those arguments include the ones constructed by Thomas Nagel (1974), Ned Block (1978), and Frank Jackson (1986).

Now, consider the transitions of the theories of light in the nineteenth century from the classical particle theory to Fresnel's wave theory to Maxwell's electromagnetic theory. Scientists presented arguments for each of these theories. But pessimists determine their attitude towards the electromagnetic theory not in consideration of how strong scientists' arguments for it are but in consideration of what happened to the classical particle theory and to Fresnel's wave theory. They believe that since the classical particle theory and Fresnel's wave theory were thrown out, the electromagnetic theory will also be thrown out. Similarly, selectivists determine their attitude towards the electromagnetic theory not in consideration of how strong scientists' arguments for it are but in consideration of what happened to the classical particle theory and Fresnel's wave theory. They believe that only the common constituent of the three theories is true.

How would philosophers of mind determine their attitudes towards Maxwell's electromagnetic theory, were they philosophers of science? They would engage with the details of scientists' arguments for it. If the arguments for it are strong, they would believe that it is true, regardless of whether its predecessors were overturned. If the arguments for it are weak, they would believe that it will be ousted in toto, regardless of whether it has a common constituent with its predecessors. In short, they would determine their attitudes towards it solely in consideration of how strong scientists' arguments for it are, i.e., exactly as individualism recommends them to do.

How would pessimists and selectivists determine their attitudes towards property dualism, were they philosophers of mind? Pessimists would not engage with the details of the arguments constructed by Nagel, Block, and Jackson. They would rather be interested in whether there were theories of mind that turned out to be problematic prior to property dualism, thinking that if there were such theories, property dualism will also turn out to be problematic. Selectivists would not engage with the details of the property dualists' arguments for property dualism either. They would rather be interested in whether there is a constituent common to all the theories of mind in the history of philosophy of mind, thinking

\footnotetext{
3 Asay takes the argument from other fields of philosophy to be part of the argument from diversity. It seems to me, however, that it can be taken to be a separate argument for localism.
} 
that only the common constituent is true. Pessimists and selectivists have something interesting in common. In order to determine their attitudes towards property dualism, they investigate what happened to its predecessors.

Whose methods are reasonable, the one that philosophers of mind use or the ones that pessimists and selectivists use? The former coincides with the method that we usually use to evaluate an argument. Suppose that there are two arguments. One is intended to justify p; the other is intended to justify q. If we want to decide whether to accept or reject q, we should evaluate the argument for q, and we should not evaluate the argument for $\mathrm{p}$. This basic rule of how to evaluate an argument is observed by philosophers of mind. For example, they assess not Descartes' argument for substance dualism but the property dualists' arguments for property dualism in order to accept or reject property dualism.

The basic rule, however, is violated by pessimists and selectivists. For example, they evaluate not scientists' arguments for the electromagnetic theory but instead scientists' arguments for its predecessors in order to accept or reject it. Pessimists argue that scientists' arguments for its predecessors were bad, so scientists' arguments for it are also bad. Selectivists argue that scientists' arguments for its predecessors were not terribly bad, so scientists' arguments for it are not terribly bad either. The ways pessimists and selectivists determine their attitudes towards the electromagnetic theory are bizarre from the perspective of those who abide by the basic rule.

In sum, Asay's argument from other fields of philosophy collides with localism, which allows for a local pessimistic induction and a local selective induction, but goes hand in hand with individualism, which says that we should evaluate scientists' arguments for a present theory, not their arguments for its predecessors, to determine whether it is true or false.

Thus far I have argued that the argument from diversity, the argument from disunity, the argument from hasty generalizations, and the argument from other fields of philosophy support separate treatments of successive theories in the same scientific discipline. However, they also support separate treatments of multiple present theories in the same scientific discipline. For example, the general theory of relativity is not reducible to the kinetic theory. So if realists and antirealists take the argument from disunity seriously, they should not be localists but instead individualists about the general theory of relativity and the kinetic theory, even though they belong to the same discipline. I will not, however, flesh out this line of objections to localism because they can be extrapolated from my previous objections to localism sketched above.

Finally, I must admit that all those objections do not apply to localism when localists evaluate a single scientific claim. However, I must point out that when they evaluate a single scientific claim, they should dismiss pessimistic and selective inductions just as flatly as individualists do. For example, when they evaluate the single scientific claim that continents move around, they should not consider previous claims about the motion of continents at all. They should rather look into scientists' arguments for it.

\section{Objections and Replies}

Localists might argue that there is an advantage of localism over individualism. Individualists' unit of evaluation is fixed, i.e., it is always a single theory. By contrast, localists' unit of evaluation is not fixed. It can be a discipline, a sub-discipline, or a scientific claim, depending on the details of disciplines, sub-disciplines, and scientific claims. It is more reasonable to change the scope of evaluation on a case-by-case basis than not to change it at all.

This objection to individualism has the following three problems. First, it is not available to Asay, given that he proposes that philosophers of science should communicate with philosophers of other fields of philosophy. Philosophers of mind never change the scope 
of their evaluation. It is not the case, for example, that they evaluate substance dualism and property dualism collectively on the grounds that they are just different forms of dualism, and that they evaluate philosophical behaviorism, the identity theory, and functionalism individually on the grounds that they are different forms of materialism.

Second, as noted earlier, localists dismiss pessimistic and selective inductions when they evaluate a scientific claim. So changing the scope of evaluation has a grave consequence, viz., localists sometimes regard pessimistic and selective inductions to be legitimate and at other times to be illegitimate. It is not clear under what conditions they are legitimate and illegitimate. It is problematic to suggest that they are legitimate when localists evaluate a discipline or sub-discipline, and that they are illegitimate when localists evaluate a single claim. Localists should specify the conditions under which pessimistic and selective inductions are legitimate and illegitimate independently of how the unit of evaluation is determined.

Third, changing the unit of evaluation means that localists sometimes evaluate a discipline or sub-discipline, which in turn means that they sometimes violate the basic rule of how to evaluate an argument. If scientists have presented arguments for q, we should evaluate those arguments in order to determine whether $\mathrm{q}$ is true or false. We should never evaluate scientists' arguments for $\mathrm{p}$ and then claim that since the arguments for $\mathrm{p}$ are weak, $\mathrm{q}$ is unwarranted. It follows that the alleged advantage of localism is actually a disadvantage of it.

Localists might retort that we can evaluate scientists' arguments for $\mathrm{p}$ and their arguments for q collectively in certain cases. If the former closely resemble the latter, and if the former are weak, we are entitled to conclude that the latter are also weak. Thus, we can evaluate scientists' arguments for the caloric theory and their arguments for the kinetic theory collectively, and say that since the former are bad, the latter are also bad.

This defense of a collective evaluation, however, runs counter to Asay's aforementioned arguments for localism. For example, he argues that scientists' arguments for the existence of strings are different from their arguments for the existence of mitochondria, so we should evaluate them independently of each other. In Section 4.1., I replied that scientists' arguments for the caloric theory are also different from their arguments for the kinetic theory, so we should also evaluate them independently of each other. It is to give up localism for localists to say that they are similar, so they can be evaluated collectively. After all, if they say so, they should also say that scientists' arguments for the existence of strings are also similar to their arguments for the existence of mitochondria, so they can also be evaluated collectively.

An anonymous referee of this journal raises the following interesting objection. Individualism clashes with Duhem's thesis, which holds that auxiliary hypotheses are required in order to render a theory predictive. How can we seriously hold that the unit of evaluation is a single scientific theory? We should not just use judgements like ' $\mathrm{T}$ is consistent with the rest of science,' at least from a realist perspective, because consistency is not much of a virtue if the rest of science is false. Moreover, consistency might not be expected if the rest of science is merely approximately true.

This objection is built upon a somewhat uncharitable interpretation of individualism. Individualism asserts that the unit of evaluation in the scientific realism debate is a single scientific theory, which is not to deny that auxiliary assumptions are required to derive testable implications from a theory. Suppose that $\mathrm{T}_{1}$ issues testable consequences in conjunction with $\mathrm{A}_{1}$ and $\mathrm{B}_{1}$, that some testable consequences agree with observations, and that others disagree with observations. Suppose that $\mathrm{T}_{2}$ issues testable implications in conjunction with $\mathrm{A}_{2}$ and $\mathrm{B}_{2}$, and that testable consequences have so far agreed with observations. Individualism asserts that from the fact that $T_{1}$ is disconfirmed, it does not 
follow that $T_{2}$ will be disconfirmed, and that from the fact that $T_{2}$ has been confirmed so far, it does not follow that $T_{1}$ is confirmed. In other words, the epistemic status of $T_{1}$ is not affected by the epistemic status of $\mathrm{T}_{2}$, and vice versa. Consequently, when we take an epistemic attitude towards $T_{1}$, we should not take the epistemic status of $T_{2}$ into account, and vice versa.

Moreover, the referee's objection above applies not only to individualism but also to localism. How can we evaluate a single scientific claim or a single scientific discipline? A single scientific claim might not be able to meet the tribunal of experience alone! A scientific discipline might need another scientific discipline to entail testable implications. I suppose that Asay would defend localism along the line I sketched above. In any event, even if the referee's objection undermines individualism, it is entirely a separate issue whether it also undermines the main thesis of this paper. In other words, even if Duhem's thesis conflicts with individualism, as the referee suggests, it might still be true that individualism is a better framework for the scientific realism debate than localism.

\section{Conclusion}

Localism comes down to the motto that "what goes for one science need not go for others" (Asay, 2106: 6). Asay has constructed impressive arguments to support localism and undermine globalism. It is my analysis, however, that they undercut localism as well as globalism. This unfortunate consequence stems from the fact that localism allows for a collective evaluation of scientific theories.

Individualists argue that what goes for a theory need not go for another theory, and hence that what goes for a past theory need not go for a present theory in the same discipline as well as that what goes for a present theory need not go for another present theory in the same discipline. My argument for individualism is simple: if we want to take an attitude toward a theory, we should evaluate scientists' arguments for that very theory and should not evaluate scientists' arguments for other theories.

Pessimists and selectivists, global or local, are history-chauvinists in that they look to past theories in order to determine their attitudes towards present theories. By contrast, individualists are argument-chauvinists in that they look to scientists' arguments for present theories to determine their attitudes towards them. Individualists observe the basic rule of how to evaluate an argument, whereas pessimists and selectivists do not. Pessimists and selectivists have places under the localist framework, but not under the individualist framework. Therefore, realists and antirealists should choose individualism over localism as the framework of their debates.

\section{References}

Achinstein, Peter (2002). “Is There a Valid Experimental Argument for Scientific Realism?”, Journal of Philosophy 99 (9): 470-495.

Asay, Jamin (2016). "Going Local: A Defense of Methodological Localism about Scientific Realism,” Synthese. https://doi.org/10.1007/s11229-016-1072-6.

Block, Ned (1979). "Troubles with Functionalism", Minnesota Studies in the Philosophy of Science 9: 262-325.

Cruse, Pierre, and David Papineau (2002). "Scientific Realism without Reference", In Michelle Marsonet (ed.). The Problem of Realism. Aldershot, U.K.: Ashgate. 
Enfield, Patrick (2008). Review of P. Kyle Stanford's Exceeding Our Grasp: Science, History, and the Problem of Unconceived Alternatives, The British Journal for the Philosophy of Science 59 (4): 881-895.

Fitzpatrick, Simon (2013). "Doing Away with the No Miracles Argument", in V. Karakostas and D. Dieks (eds.), EPSA11 Perspectives and Foundational Problems in Philosophy of Science. The European Philosophy of Science Association Proceedings 2: 141-151. Springer International Publishing Switzerland.

Jackson, Frank (1984). “What Mary Didn’t Know”, Journal of Philosophy 83 (5): 291-295.

Hempel, Carl (1966). Philosophy of Natural Science. Englewood Cliffs, NJ: Prentice-Hall, Inc.

Kitcher, Philip (1993). The Advancement of Science: Science without Legend, Objectivity without Illusions. New York: Oxford University Press.

Laudan, Larry (1977). Progress and Its Problems: Towards a Theory of Scientific Growth. California: University of California Press.

Lipton, Peter (2001). "Quests of a Realist" (Review Symposium on Psillos's Scientific Realism: How Science Tracks Truth), Metascience 10: 347-353.

Mach, Ernst (1911). History and Root of the Principle of the Conservation of Energy (Jourdain P. E. B., Trans.). Chicago: Open Court Publishing Company.

Magnus, P. D. and Craig Callender (2004). "Realist Ennui and the Base Rate Fallacy", Philosophy of Science 71 (3): 320-338.

Nagel, Ernest (1979). The Structure of Science: Problems in the Logic of Scientific Explanation. Indianapolis, Indiana: Hackett Publishing Company.

Nagel, Thomas (1974). “What is It like to Be a Bat?", Philosophical Review 83 (4): 435-450.

Park, Seungbae (2017). "Selective Realism vs. Individual Realism for Scientific Creativity", Creativity Studies 10 (1): 97-107.

(2018a). "Justifying the Special Theory of Relativity with Unconceived Methods", Axiomathes 28 (1): 53-62.

(2018b). "In Defense of the Epistemic Imperative", Axiomathes 28 (4): 435-446.

Poincaré, Henri (1905/1952). Science and Hypothesis. New York: Dover.

Psillos, Stathis (1999). Scientific Realism: How Science Tracks Truth. New York: Routledge.

Putnam, Hilary (1975). Mathematics, Matter and Method (Philosophical Papers, vo. 1), Cambridge: Cambridge University Press. 
Roush, Sherrilyn (2010). "Optimism about the Pessimistic Induction", In New Waves in Philosophy of Science. P. D. Magnus and Jacob Busch (eds.), Basingstoke: Palgrave Macmillan.

Ruhmkorff, Saumel (2013). "Global and Local Pessimistic Inductions", International Studies in the Philosophy of Science 27 (4): 409-428.

Stanford, P. Kyle (2015). "Catastrophism, Uniformitarianism, and a Scientific Realism Debate That Makes a Difference”, Philosophy of Science 82 (5): 867-878.

Worrall, John (1989). "Structural Realism: The Best of Both Worlds", Dialectica 43 (1-2): 99-124.

Wray, K. Brad (2013). "Pessimistic Induction and the Exponential Growth of Science Reassessed”, Synthese 190 (18): 4321-4330. 